\title{
Aliados y enemigos. Misiones protestantes, acogida liberal y reacción católica en El Salvador
}

(2)

"Creo que este Estado (El Salvador) es el más pequeño pero el más densamente poblado no sólo de Centro América, sino de toda Latino América. Su gobierno es progresista y liberal, pero la Iglesia Romana, como hace una amante en esta situación, se defiende a si misma por todos los medios posibles, $y$ no olvida su máxima 'el fin justifica los medios'. Afortunadamente el gobierno nos protege, $y$ parece simpatizar con nuestro trabajo.

Francisco Penzotti, Agente de la Sociedad Bíblica Americana, $1896^{1}$

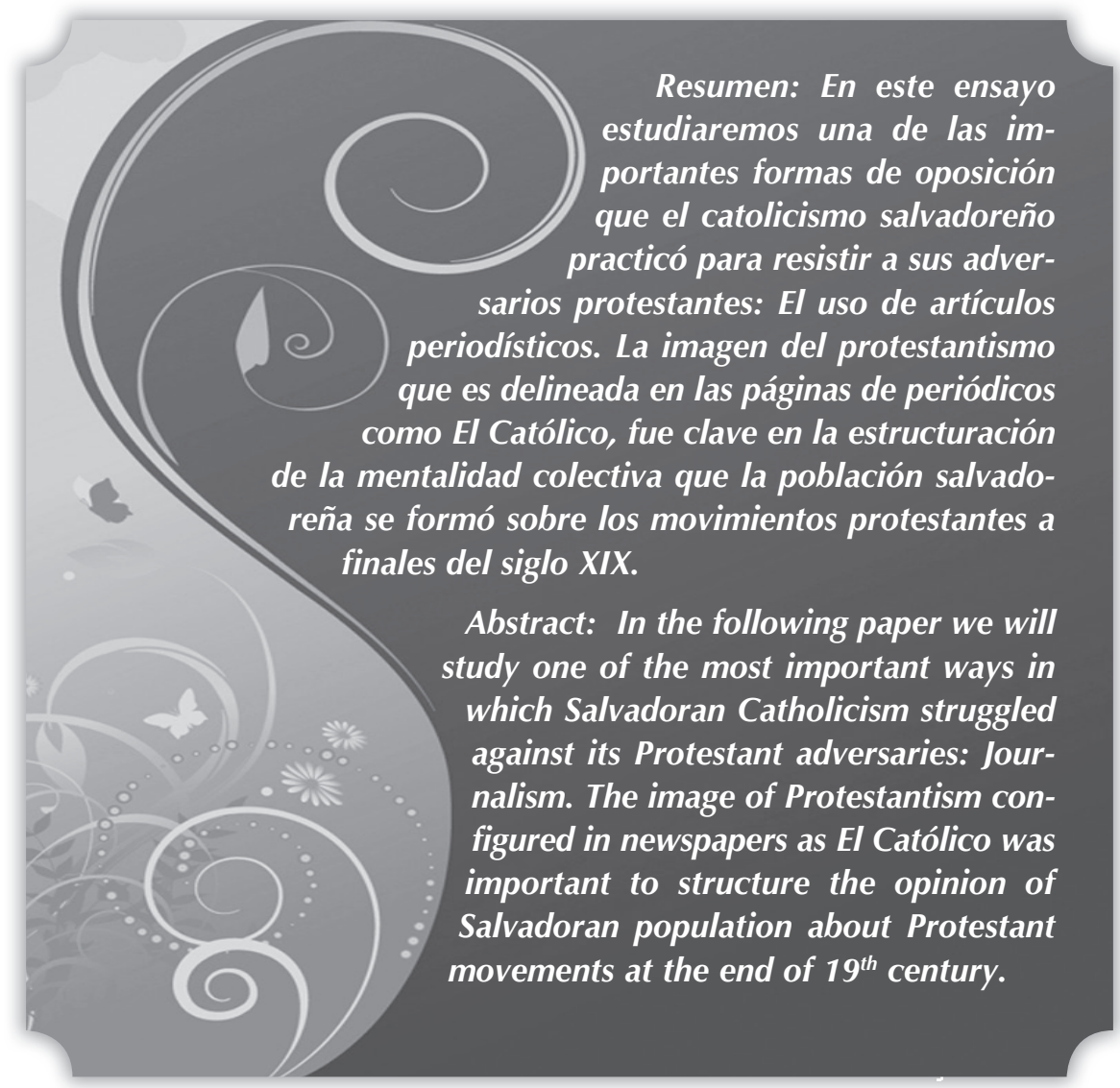




\section{Introducción}

- I estudio de las disidencias -religiosas o no- es todavía un campo relativamente inédito en El Salvador. Entendemos como tales aquellos grupos minoritarios cuyas visiones del mundo no comparten la visión tradicional de los grupos de poder en turno, ya sea este civil o religioso, oponiéndosele. El estudio de los disidentes es importante, entre otras cosas, para poder hacer visibles sus formas de participación en la construcción de la modernidad salvadoreña y el aporte que hicieron en la conformación inicial de la sociedad democrática que aún no terminamos de construir. A esas minorías disidentes pertenecieron a finales del siglo XIX grupos tales como la Francmasonería, los Liberales, Librepensadores y Misiones Protestantes. ${ }^{2}$

Movimientos como estos cuatro mencionados han sido estudiados por los historiadores franceses Cochin y Furet. ${ }^{3} \mathrm{~A}$ juicio de Jean Pierre Bastian, "Cochin, en particular, las consideró bajo el término explicativo de "sociedades de ideas" (sociétés de pensée ) -vale decir, como formas modernas de sociabilidad- que ofrecieron nuevos modelos asociativos, en medio de una sociedad globalmente organizada en torno a una estructura corporativa jerárquica (órdenes) y compuesta en esencia por actores sociales colectivos... portadoras de la modernidad, en el sentido de que estructuraban nuevas formas de organización de lo social, ya no centradas sobre los antiguos cuerpos, sino en el individuo como actor político y social". ${ }^{4}$ Estas sociedades tenían, como rasgo en común, una marcada oposición a las prácticas hegemónicas de la Iglesia Católica, promovían la educación secular, la libertad de cultos, el libre pensamiento y la libertad de prensa, y en muchas ocasiones se les descubre trabajando en alianza para defenderse o atacar el catolicismo.

En este contexto, el establecimiento y posterior desarrollo del Protestantismo en El Salvador ha sido poco estudiado. Lo que hasta el presente se encuentra sobre el tema son reseñas apologéticas, escritas por grupos confesionales, desprovistas de rigor crítico. Por ejemplo, es un hecho desconocido hasta el momento que en El Salvador las Sociedades Protestantes jugaron un papel fundamental en el desarrollo de nuestro proyecto de modernidad liberal a finales del siglo XIX, y que lo hicieron en confrontación con el poder establecido de la Iglesia Católica. Otro aspecto digno de ser investigado y reevaluado para establecer su validez, es la visión tradicional de la inserción del protestantismo dentro del marco de una teoría de la conspiración del imperio norteamericano. El propósito habría sido adormecer las masas para impedir la toma de conciencia 
necesaria para que fueran desarrollados procesos revolucionarios de cambio social en las naciones latinoamericanas. También se desconoce el impacto, y se valora muy poco, el continuo aporte de las Iglesias protestantes en la construcción del ciudadano salvadoreño a través de sus procesos de conversión y regeneración individual.

Por otro lado, en medio de toda la actividad de los grupos disidentes al catolicismo a finales del siglo XIX, destaca un aspecto que, observando esta actividad de cerca se hace evidente: la colaboración que a la inserción del Protestantismo en El Salvador ofrecieron los movimientos liberales, los francmasones y los librepensadores. Desde su llegada a El Salvador, a finales del siglo XIX, las Sociedades Protestantes fueron apoyadas por los gobiernos liberales en turno y desarrollaron prácticas democráticas que ayudaron a configurar lo que ahora conocemos como nuestra Sociedad Civil. De manera espontánea establecieron espacios abiertos de discusión, e imprimieron panfletos y periódicos propios en donde plasmaban sus ideas. La Iglesia Católica salvadoreña reaccionó ferozmente ante esta situación resistiendo el despliegue protestante en el seno de la sociedad de esa época. Así lo venía haciendo por años en contra de la Francmasonería y el Liberalismo, por lo que la desacreditación, como recurso en contra de los movimientos protestantes, no se hizo esperar.
En este ensayo estudiaremos una de las importantes formas de oposición que el catolicismo practicó para resistir a sus adversarios protestantes: El uso de artículos de periódico de corte apologético, no siempre fundamentados, pero sí valiosos para contrarrestarlos y desgastar la amenaza que estos pudieran representar. La imagen del protestantismo que es delineada en las páginas de periódicos como El Católico $^{5}$, fue clave en la estructuración de la mentalidad colectiva que la población salvadoreña se formó sobre los movimientos protestantes a finales del siglo XIX. Esta imagen, aún en nuestros días, permanece fuertemente arraigada. Un hecho notable a destacar es la clara intencionalidad de El Católico por mostrar que los protestantes eran parte del mismo grupo de enemigos al que pertenecían los liberales y francmasones; ciertamente alianza real en esa época, pero impensable para el protestantismo de nuestros días.

Finalmente este ensayo se enmarca dentro de un trabajo de mayor envergadura que pretende explorar el fenómeno del protestantismo en El Salvador desde una perspectiva de larga duración, en el período de tiempo que va de finales de siglo XIX hasta aproximadamente el cuarto decenio del siglo $X X$. Fue en esta última época en la cual regímenes autoritarios y conservadores dieron un giro opuesto a la visión del mundo liberal y el 
movimiento protestante, dio giros inesperados y diferentes al ser com-

parados con la inicial visión liberal de sus orígenes.

\section{Importancia de Centroamérica para los protestantes}

El deseo de suministrar Biblias a través de todo Estados Unidos y el mundo "fue profundo y constante desde los primeros días de nuestra República" ${ }^{\prime \prime}$ expresó una de las organizaciones norteamericanas que hasta el presente lo hace con éxito. La Sociedad Bíblica Americana (SBA), se constituyó en el año 1816 en la ciudad de Nueva York con el único objetivo de "fomentar una amplia circulación de las Sagra- das Escrituras" ${ }^{\prime 7}$. Pasaron 46 años desde de su fundación para que la SBA considerara la posibilidad de distribuir Biblias protestantes en lo que ellos consideraban "el Área del Caribe", conformada por Guatemala, Honduras, El Salvador, Nicaragua, Costa Rica, Panamá, Colombia y Venezuela. ${ }^{8}$ En 1854, el Reporte Anual número 38 de la SBA concluía:

Y más cerca de casa, entre los Estados de Centro y Sur América, la Junta Directiva siente que ha llegado el tiempo para incrementar los esfuerzos. Los movimientos a favor de la libertad religiosa, y una grandemente incrementada demanda de Escrituras, alienta la esperanza de que medidas vigorosas, una vez adoptadas, puedan resultar en mucho bien. Una pequeña donación de \$3,000 ha sido efectuada, y mucho mas será dado, tan pronto como una persona adecuada sea encontrada, la cual supervisará el trabajo. ${ }^{9}$

Estos movimientos a favor de libertad religiosa mencionados, abrían espacios para el trabajo de esta Sociedad Bíblica protestante, en un ambiente en donde el catolicismo era la religión oficial. Y el Reporte número 44 del año 1860 se expresaba así:

Sobre Centro y Sur América, también, por largo tiempo maldecidas con un sacerdocio ignorante e intolerante y con gobiernos cabalgados por sacerdotes, un prospecto brillante parece amanecer. Estos bellos países, con una población agregada de muchos millones, cuyas lenguas han sido por siglos enriquecidas por las más admirables versiones de las Escrituras, han recibido por parte de las Iglesias Reformadas, de esta y de otras tierras, menos atención que cualquier 
otra parte del mundo. Esto no debe ser más la vergüenza de nuestro Protestantismo. Emprendedoras misiones han sido recientemente establecidas en varios puntos, y otras han de seguir, reconociendo la Biblia como el instrumento principal por el cual las masas pueden ser alcanzadas, atendiendo a esta Sociedad con una oferta adecuada del Sagrado Volumen. Lo que los Gerentes han hecho para esta porción del campo externo ya ha sido establecido. Ellos proponen ir aún más lejos en el empleo de sus propias agencias, creyendo que los esfuerzos sistemáticos en la mayoría de esos países será seguido por los más felices resultados. ${ }^{10}$

Por lo tanto, en Diciembre de 1862 el Comité de Agencias de la SBA recomendó a Mr. Frederick Hicks, que hasta entonces residía en Panamá, su asignación por un año como Agente para Centro América, habiendo sido ésta la primera zona del Área del Caribe a ser considerada para una distribución. La Junta Directiva de la Sociedad había "observado ansiosamente cualquier apertura favorable en los Estados Centro Americanos". ${ }^{11}$ Aparentemente la apertura deseada llegó. Gobernaba en El Salvador, desde 1859, el General Gerardo Barrios, liberal radical y gran defensor de la causa de la Unión Centroameri- cana. Sin embargo, en 1863 estalló la guerra entre el gobierno de Barrios y el gobierno de Guatemala que presidía el conservador Rafael Carrera. ${ }^{12}$ Barrios fue derrotado y tuvo que exiliarse en Panamá. Con apoyo del gobierno guatemalteco se estableció en El Salvador un nuevo régimen, dirigido por Francisco Dueñas. La SBA hace referencia a dos cartas que calificaron como inquietante esta nueva conformación política. La primera, fechada el 9 de Febrero de 1863, cita que Hicks se había expresado en estos términos a menos de dos meses de su nombramiento:

La invasión de San Salvador se ha dado, y en esa provincia, y en Costa Rica. El poder del clero probablemente se incrementará en perjuicio de la causa de la Biblia, los prospectos no son halagadores. ${ }^{13}$

Mr. Hicks, quien aún no se había establecido en la zona que la SBA le habia asignado, declinó la oferta. La segunda referencia es de Abril de este mismo año en la que citan a Hicks: "dando un recuento del inestable estado político en Centro América y que al presente no hay apertura para una agencia allí". ${ }^{14}$ En consecuencia, "El Comité acudió a otro amigo de la Sociedad, William H. Norris quien había tra- 


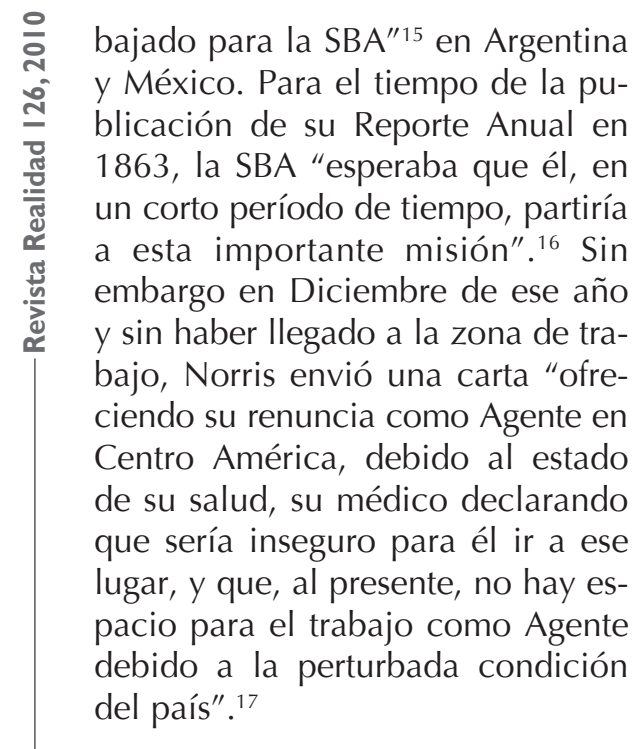

Precisamente en 1864 en El Salvador, bajo la dirección de Francisco Dueñas, y habiendo sido derrocado definitivamente el gobierno liberal radical, se redactó una nueva Constitución que incluía los principios del ideario del Liberalismo católico. ${ }^{18}$ Dueñas mantuvo relaciones cordiales con la Iglesia Católica, y reprimió violentamente a sus opositores radicales hasta que fue derrocado en 1871. El esfuerzo de distribución organizada de Biblias por la SBA durante el período de 1864 a 1871 fue totalmente nulo. Los dirigentes de la SBA escribieron acerca de su trabajo en Centro América en 1865: "Nuestras expectativas no han sido realizadas... El Comité no ha podido encontrar una persona para este campo realmente, y por la información recibida desde que fue emitido el último Reporte, se ofrece poca esperanza de tener una operación exitosa...". ${ }^{19}$

Observando los hechos acaecidos entre los años 1863 y 1865 , se puede deducir que la SBA tenía claro que la presencia de regímenes afines al Liberalismo radical y secularizante favorecía la penetración de la Biblia, y por tanto de la fe protestante. Por tanto, la caída del régimen de Gerardo Barrios y la inestabilidad política de la región, fue el principal obstáculo para que desde mediados del siglo XIX se iniciara la distribución de Biblias en estas tierras. El reporte del agente Hicks en el sentido de que el triunfo de los conservadores fortalecería al clero de la Iglesia Católica en contra de los intereses de la Biblia, alimenta esta idea. Muy difícil tarea debe haber estimado Hicks el enfrentamiento con una Iglesia Católica fuertemente apoyada por el poder gubernamental. $\mathrm{Y}$ es que aunque la tarea fundamental que se buscaba concretar era solamente vender Biblias, este trabajo prepararía la llegada de las organizaciones misioneras, como en efecto lo hicieron treinta años después. El enfrentamiento con el catolicismo sería inevitable y en desigualdad de condiciones sin leyes en las que apoyarse.

Durante el período de 1863 hasta 1891, el trabajo de distribución de Biblias en Centroamérica por parte de la SBA se redujo al 
envío ocasional de ejemplares distribuidos de manera voluntaria por personas que transitaban por la zona. En el año 1866, los Gerentes de la SBA concluyeron: "al presente no es conveniente asignar un Agente especial para Nueva Granada y Centro América". ${ }^{20}$ Alrededor de los años 1876-1877 "prácticamente ninguna mención fue hecha del trabajo de la Biblia en Centro América", ${ }^{21}$ excepto por una donación de 105 libros para "Mr. Flint, Cónsul de los Estados Unidos en La Unión, San Salvador"22. Aunque nuevos regímenes afines al Liberalismo radical y secularizante habían surgido en El Salvador desde 1871 y las condiciones políticas eran favorables, la dificultad de conseguir agentes para una distribución de la Biblia a mayor escala hizo menos efectiva la labor. Entre 1879 y 1880 sólo unos cuantos volúmenes fueron enviados a Centro América, "aunque los prospectos no fueron alentadores". ${ }^{23}$ Se reportó una demanda inusual de Escrituras entre los años 1882-1884, pero mayormente en Guatemala y Costa Rica debido al trabajo misionero que ya desarrollaban los Presbiterianos en esos países. Entre 1888 y 1892, el Reporte de los Gerentes de la SBA sobre la situación en Centroamérica se resumía así:

Muy limitadas oportunidades son ofrecidas para distribuir las Escrituras en Centro América, y solamente 93 volúmenes fueron enviados el año pasado a Nicaragua. Debe esperarse, si los fondos de la Sociedad lo permiten, que en el futuro cercano algunos planes que ahora están bajo consideración preparen el camino para trabajar en una escala proporcional a la necesidad actual de la gente. ${ }^{24}$

El Reporte Anual de la SBA del distribución en América Latina de la año 1893 expresaba el estado de la siguiente manera:

Rara vez han tenido el privilegio los Gerentes de presentar un recuento más satisfactorio de la distribución de la Biblia conducida bajo nuestra supervisión que la que aparece en las páginas de este Reporte en relación al trabajo de los Agentes de la Sociedad en Centro América... ${ }^{25}$

Sin embargo, para al área de Centro América, añaden:

Varios obstáculos han impedido la circulación de las escrituras en Centro y Sur América, algunas de las cuales han ya terminado mientras que otros aún son formidables. Siempre se espera amarga oposición por parte del sacerdocio. El 
fanatismo de la gente es un constante elemento de fricción. El analfabetismo, indiferencia, pobreza, guerra, dificultades de viajar y transportarse, y la falta de hombres que estén tanto disponibles como dispuestos, por causa del Evangelio, para resistir la dureza y la fatiga para llevar el pan de vida a los hambrientos, se sugieren como las razones más prominentes del porqué las Escrituras son al presente poco conocidas y leídas en los países referidos. ${ }^{26}$

Varios eventos sucedidos entre 1891 y 1892 comenzaron a abrir las puertas de la distribución en esta zona. Alrededor del año 1891, se dio un período de inestabilidad política en Venezuela, lo cual amenazaba la continuidad del trabajo de la SBA en ese lugar. Fue la guerra civil en Venezuela denominada "La Revolución Legalista" que tuvo como causa el movimiento continuista del presidente Raimundo Andueza Palacio, quien quería perpetuarse en el poder mediante una reforma constitucional. Esto provocó la salida voluntaria de ese país del Agente Joseph Norwood, quien abandonó su posición en 1892. De manera casi simultánea, los conflictos con la Iglesia Católica hicieron salir del Perú a otro agente de nacionalidad italiana Ilamado Francisco Penzotti, quien había desarrollado trabajo para la SBA por muchos años en Sur América. Habiendo quedado estos dos agentes disponibles y sin trabajo asignado, se consideró la posibilidad de contratarlos como agentes por parte de la SBA en otro lugar. Ambos fueron considerados para establecer la Agencia en Centro América. Con Agentes de tanta experiencia, la SBA iniciaba alli su trabajo con fuerza.

En El Salvador de esos días era normal leer, en el periódico $E l$ Católico, publicaciones de manera intermitente que se referían al Protestantismo como una realidad distante y decadente. El editorial de este semanario el día domingo 25 de enero de 1891, titulado "La Muerte del Protestantismo", declaraba: "el protestantismo ha entrado en un estado de descomposición que predice y asegura su próxima y definitiva muerte, desaparezcan también cuanto antes el racionalismo y la impiedad, nacidos de aquella abominable secta". ${ }^{27}$ En realidad, El Católico no consideraba al Protestantismo un enemigo muy poderoso. A sus ojos había otro de mayor peligro: la Masonería, como lo permite ver la siguiente frase: "... gran enemigo social es la Masonería. Más que al Protestantismo debe temérsela" ${ }^{28}$. También había 
triunfalismo en la visión católica del periódico; frecuentes eran las alusiones a eventos en la Europa de esos años, se detallaban anécdotas de protestantes alabando personas $y$ hechos del catolicismo, ${ }^{29}$ se reportaban las conversiones al catolicismo de protestantes prominentes, ${ }^{30}$ se acusaba debilidad entre los movimientos protestantes por causa de su falta de unidad y se les tachaba de cismáti- cos. ${ }^{31}$ Parece que la Iglesia Católica salvadoreña observaba confiadamente lo que ellos consideraban el derrumbe del Protestantismo, el cual si bien estaba vivo y con buena salud en otras regiones del mundo, era virtualmente inexistente en esta región. Si esa era la evaluación de los católicos, la realidad probaría lo contrario, pues el distante enemigo estaba a las puertas.

\section{La llegada}

"Un deseo largamente acariciado había sido para la Junta de Gerentes entrar vigorosamente a la tarea de suministrar las cinco repúblicas de Centro América con las Escrituras" $^{\prime 32}$. La tarea inicial de los dos agentes asignados por la SBA en la región, Norwood y Penzzoti, debería ser realizada "trabajando concertadamente y reuniéndose en puntos establecidos". Se les pidió "visitar en sucesión Costa Rica, Nicaragua, San Salvador, Honduras y Guatemala". ${ }^{33}$ Es más, el Comité de Agencias coincidió en que era "un tiempo favorable para explorar nuevos territorios y recomendaron que Mr. Norwood y Mr. Penzotti fueran instruidos para realizar una expedición conjunta de los estados de Centro América durante la consiguiente estación, visitando tanto como sea práctico hacerlo, los Estados de Costa Rica, San Salvador, Nicaragua, Guatemala, y Honduras". ${ }^{34}$ Este viaje exploratorio fue exitoso, a juzgar por lo que escribe la SBA en su Reporte número setenta y siete del año 1893:

La empresa fue coronada con un éxito notable, y en los consiguientes seis meses más de 11,700 copias de Biblias, Testamentos, y Porciones ${ }^{35}$ fueron vendidas, importando el producto \$2,253 10 en oro de los Estados Unidos. ${ }^{36}$

El total de libros vendidos, según este Reporte — sin tomar en cuenta Colombia- es de 12,377. Nuevamente difiere de lo expresado en los reportes del Comité de Agencias y el Reporte Anual de 1983. ${ }^{37} \mathrm{El}$ rango oscila entre 11,700 y 12,500 copias. En cualquier caso, es una cantidad importante, considerando los altos niveles de analfabetismo de la región en esa época y los pocos meses de trabajo en la zona. 


\begin{tabular}{|c|c|c|c|c|c|c|c|c|}
\hline & \multicolumn{4}{|c|}{ LIBROS VENDIDOS } & \multicolumn{4}{|c|}{ LIBROS DONADOS } \\
\hline & Biblias & Testamentos & Porciones & Total & Biblias & Testamentos & Porciones & Total \\
\hline Colombia & 634 & 522 & 1,408 & 2,564 & 43 & 53 & 101 & 197 \\
\hline Costa Rica & 570 & 400 & 2,343 & 3,313 & 8 & 27 & 116 & 148 \\
\hline Nicaragua & 439 & 464 & 1,868 & 2,771 & 6 & 11 & 32 & 49 \\
\hline Honduras & 81 & 139 & 525 & 745 & 38 & 29 & 70 & 146 \\
\hline San Salvador & 331 & 401 & 1,661 & 2,393 & 4 & 25 & 74 & 104 \\
\hline Guatemala & 493 & 493 & 1,719 & 2,705 & 4 & 8 & 303 & 315 \\
\hline Totales & 2,548 & 2,419 & 9,524 & 14,941 & 100 & 154 & 705 & 959 \\
\hline
\end{tabular}

Fuente: American Bible Society, Seventy-Eighth Annual Report of the American Bible Society, New York, American Bible Society, 1894, p. 107.

Por su parte, el Reporte Anual de 1894 se refirió a estas actividades de la siguiente manera:

Corta mención se ha hecho en el último reporte de las señales de éxito que atendieron la expedición de los señores Norwood y Penzzoti en Centro América, pero lo suficiente para mostrar amplio estímulo a la Sociedad en continuar sus operaciones y ponerlas sobre una base permanente. ${ }^{38}$

En su oportunidad, el agente Norris elaboró un detallado recuento de la expedición centroamericana. En relación a Nicaragua, lugar desde donde se dirigió a El Salvador, se detalla que Penzotti entró por el puerto de Corinto. Los oficiales del Gobierno nicaragüense prohibían en esa época toda adoración religiosa que no fuera la Católica. En Managua Penzotti se entrevistó "con el Presidente de la República, el Presidente del Senado, El Ministro de Relaciones Exteriores y muchos congresistas y senadores para discutir sobre el tema de la libertad religiosa y el matrimonio civil". ${ }^{39}$ Visitó Managua, León, la reservación Mosquitia y Blufields, entre otros lugares. En Greytown recibió el apoyo del Gobernador del Puerto de San Juan del Norte, quien debido a sus "visiones muy liberales" 40 fue la excepción a la regla del prohibir otras adoraciones religiosas, aparte de la católica, en Nicaragua. En El Salvador el trabajo de Penzotti resultó ser exitoso, pues se reporta:

Ésta, aunque la más pequeña de las cinco Repúblicas en Centro América, es una de las más importantes. Vendimos más libros que en ninguna otra, y Mr. Penzotti ha tenido un notorio éxito en los servicios de predicación que ha sostenido en la capital. En el curso de tres semanas, su congregación se ha incrementado de alrededor de treinta 
a más de doscientos, y muchas personas de varios círculos de la sociedad, desde el más alto al más bajo, incluyendo editores de periódicos, insistieron en que permaneciera con ellos, y prometieron cooperar, tanto con dinero como con su influencia, si regresaba y trabajaba con ellos. ${ }^{41}$

Por todo lo anteriormente descrito, y "como es usualmente el caso, los sacerdotes Romanistas se enfurecieron y publicaron todo tipo de errores relativos a él y la Biblia, tuvieron éxito en conducir dos turbas en diferentes oportunidades para atacarlo en las calles...". ${ }^{42}$ Al mismo tiempo, "muchos otros pueblos y ciudades en San Salvador fueron visitados y muchas copias fueron vendidas, de tal manera que concluyó que éste es uno de los más importantes campos en la América Española". ${ }^{43}$

El Comité de Agencias de la ABS también reportó el recorrido exploratorio: "El trabajo logrado en las repúblicas de Centro América durante estos cinco meses muestra conclusivamente que no hay campo más importante en ninguno de los países de la América Española, ${ }^{44}$ y añadió:

El Comité deja constancia de su satisfacción con el trabajo que hasta ahora ha sido reportado como logros en Centro América durante la última parte de $1892 \ldots$ El trabajo conjunto de Mr. Norwood y Mr. Penzotti debe terminar pronto y será una cuestión de gran importancia qué arreglo futuro puede ser el mejor hecho para el territorio de Centro América, Colombia y Venezuela... ${ }^{45}$

Mr. Norwood regresó a Venezuela y Penzotti fue nombrado Agente para Centro América en Diciembre de 1893. Sin embargo no ocupó la posición hasta 1895, habiéndose tomado ese tiempo para reunir su familia desde los Estados Unidos y Perú, para finalmente establecerse en Guatemala. Las dificultades del trabajo de Penzotti se incrementaron en 1896 debido a la dificultad de conseguir colportores ${ }^{46}$ que ayudaran a su trabajo, además de otros condicionantes que no lo hacían sencilla la tarea, tales como los siguientes:

... los costos de vida son altos, viajar y transportar libros es difícil y costoso, y el analfabetismo, así como los prejuicios contra todo lo que no haya sido sancionado por los sacerdotes es un factor constante de interferencia con la venta de Escrituras $^{47}$. 
Penzotti fue trasladado a Cuba a finales de 1899. Durante el período transcurrido entre 1894 y 1900, la agencia en Centro América distribuyó 60,316 ejemplares entre Biblias, Nuevos Testamentos y Porciones. ${ }^{48}$

\title{
3. La reacción católica frente a la llegada del Protestantismo
}

Durante todo este tiempo, la Iglesia Católica salvadoreña no fue una simple espectadora de las actividades protestantes. El enemigo había llegado con intenciones de quedarse y había que hacer lo necesario para evitar por cualquier medio la aceptación y el desarrollo de una religión que podía amenazar privilegios con los que habían contado durante siglos. Una de las herramientas más eficientes que utilizaron para atacar la llegada del enemigo fue la prensa escrita. A través de las páginas de periódicos como El Católico podemos descifrar las estrategias para lograrlo: desacreditar al adversario mediante la construcción de un imaginario colectivo que perfilara al Protestantismo como una religión infernal, propagadora de literatura y Biblias falsas y/o adulteradas, abanderada de peligrosas libertades, perseguidora de la Iglesia, y aliada de enemigos reconocidos del catolicismo tales como la Francmasonería y los Liberales. El Católico definía el rol de la prensa religiosa de esta manera:

\begin{abstract}
...lluminar la vista de los centro-americanos, para que, contemplando el sol de la libertad de Cristo, sacudan de una vez por todas el pesado yugo del liberalismo político y sectario, y para que, disfrutando de los preciosos dones de la paz y del progreso positivos, sea colocada Centro América en el catálogo de las naciones cultas y libres. ${ }^{49}$
\end{abstract}

Es muy clara la intencionalidad de la prensa católica. Su enemigo declarado es el Liberalismo, y junto a él todo movimiento sectario en relación a sus concepciones religiosas y visión del mundo. La desa- creditación del Protestantismo debía pasar por una definición absoluta de su origen, señalándola como una religión no nacida por revelación divina, sino por el contrario, como originada en el mismo infierno:

El establecimiento del protestantismo, por el contrario, revela su origen infernal, pues se llevó a término, halagando las pasiones más perversas, conculcando los derechos más sagrados, valiéndose de los medios más brutales. ${ }^{50}$ 
La relación entre los distintos periódicos católicos de la región centroamericana era manifiesta y muy estrecha. Esto se puede constatar por la cantidad de editoriales y artículos, que habiendo sido escritos en otro país, eran reproducidos en el nuestro en el transcurso de este período estudiado. Parece clara la intención de los periódicos en mostrar un frente común contra el Protestantismo, y no sólo eso, sino también en mostrar uniformidad en la visión que del mismo se transmitía, siempre descalificándolo. Así por ejemplo, El Católico reproduce en su edición del 26 de Febrero de 1893 un artículo de su colega nicaragüense El Sentimiento Católico. En éste se comenta y reprocha el apoyo que las autoridades de San Juan del Norte, Departamento del vecino país, daban al establecimiento del Protestantismo. En ese lugar, un maestro protestante había sido asignado a la escuela del lugar. Este he- cho se atribuye al espíritu "sectario" del Gobernador Intendente, "que en vez de asistir, como católico, al templo católico, asiste, con escándalo de los buenos, al templo protestante, y toma parte en sus farsas de culto".$^{51}$ A lo que se refiere este artículo es al apoyo que, como antes ya señalamos, Penzotti obtuvo durante sus trabajos en Greytown, cuyo Gobernador, dadas sus ideas liberales -añade el articulista-, "en vez de proteger la Religión del Gobierno de la nación, como podía hacerlo con el derecho que le da la libertad de cultos que allá existe, emplea esa libertad en bien de las sectas impías, cuyo origen vergonzoso es bastante para que ningún hombre serio tenga simpatías por ella". ${ }^{52}$

En este mismo número, El Católico anuncia la próxima Ilegada del Agente Penzotti en su "Sección de lo Interior", bajo el subtítulo "Otra Propaganda", de esta manera:

Una persona fidedigna ha dado a la redacción de este periódico la noticia de que ha llegado, o esta para llegar, de Nicaragua, un ministro protestante vendedor de Biblias y Evangelios adulterados según la doctrina de Lutero. Dicho traficante, lo mismo que los masones, se vale de la mentira y del dolo; pues dice que son libros muy buenos, muy católicos, muy piadosos... para engañar a los sencillos. ${ }^{53}$

Puede verse como el texto anterior asocia al Protestantismo con la Francmasonería cuando lo acusa de "traficante, lo mismo que los masones".${ }^{54}$ Como ya se ha dicho, Penzotti venía de Nicaragua en la continuación de su viaje explora- torio por América Central, pero El Católico definió los resultados de su estadía en aquel país como un mal negocio que "dio por resultado el más solemne desprecio para los aventureros luteranos, que burlados por el pueblo y arrojados con in- 
dignación de muchas casas donde llegaban con sus libracos, se vieron obligados a liar sus maletas e irse con su música a otra parte".$^{55}$ Posteriormente, en la edición del 12 de Marzo del mismo año, confirma el periódico la llegada de Penzzoti, proporcionando -casi con carácter de denuncia pública- su nombre y apellido, así como el lugar donde residía:

\section{Francisco Pinzotti ${ }^{56}$ se llama el Ministro Protestante que ha venido de Nicaragua expulsado por el pueblo, a vender sus Biblias y libros del Evangelio falsos. Vive en la calle de Zaldaña, al Poniente, frente a la casa de Santos Martínez Robelo, en la casa de la señora Francisca Ramos. ${ }^{57}$}

Solo unas semanas después de la llegada de Penzotti, la caracterización del Protestantismo comienza a ser delineada por El Católico. El periódico denuncia un supuesto listado de prácticas arbitrarias que estuvieron en vigor por muchos años en Inglaterra contra los católicos a fin de dar facilidades para que el Protestantismo se estableciera. Veamos algunas de ellas:

Pena de la vida, a quien oiga misa y se confiese... Pena de la vida, a quien admita la supremacía del Papa, negando la de la Reina... Los católicos deberán asistir al oficio protestante, so pena de 6,500 libras esterlinas al año, el pobre será condenado a cárcel, hasta que muera de hambre... El sacerdote que sea cogido vivo, será colgado hasta que esté medio muerto, y luego se le cortará la cabeza, se le descuartizará, y le serán separadas sus entrañas... Un padre católico que confíe a sus hijos a un preceptor católico será condenado a 300 francos anuales de multa... ${ }^{58}$

Es de suponer que la feligresía católica, ante tales supuestas revelaciones en relación a la conducta protestante, temía la posibilidad de la llegada de estos, pues podría poner en peligro los valores y prácticas católicas imperantes hasta entonces, tales como la misa, la confesión y la autoridad del Papa. También podían temer la posibilidad de perder sus hijos y aún la propia vida a mano de esta secta. La guerra contra el protestantismo estaba declarada y una herramienta poderosa estaba siendo utilizada, la prensa escrita. ${ }^{59}$

Dos semanas después de denunciar la llegada del colportor de la SBA, en su edición del 12 de marzo, El Católico había proporcionado detalles adicionales de su 
trabajo, y pasa a condenar y descalificar sus actividades. Esta vez el enemigo ya no está sólo, se ha aliado con otros enemigos de la Iglesia.

Dicho ministro luterano, auxiliado eficazmente por los adversarios constantes del catolicismo entre nosotros, ha comenzado a ejercer su ministerio por todas partes con el celo que inspiran el odio a la religión y el interés personal. El nuevo misionero, a usanza de los nego- ciantes, reparte una hoja suelta, editada en la imprenta de El Cometa, en la que anuncia su mercancía y garantiza al comprador los libros de la Sociedad Bíblica Americana. ${ }^{60}$

Al mismo tiempo se informaba el inicio de las conferencias de Penzotti a las cuales, se informó, asistieron una treinta personas, mujeres incluidas, así como alguien notable identificado como el Dr. Rafael Reyes. ${ }^{61}$ Asimismo se advertía:

Es grave delito para el católico comprar, leer o conservar los libros de los protestantes que tratan directamente de la religión; mucho más las biblias y evangelios que, mutilados y falseados según los errores protestantes, dejan de ser libros divinos... La Iglesia ha colocado, con mucha razón, en el Índice de obras prohibidas, las Biblias y demás libros sagrados de los protestantes. ${ }^{62}$

Muy ingeniosa tenía que ser la estrategia de descalificación del recién Ilegado Protestantismo. El trabajo de la SBA consistía en la venta de ejemplares de una Biblia que prácticamente tenía el mismo contenido que la católica. Como se sabe, la diferencia es la adición por parte del catolicismo de un reducido grupo de libros polémicos conocidos como libros apócrifos o de dudosa inspiración divina. Si la fe protestante tenía como base la misma Biblia, y esta era la plataforma de trabajo de la SBA, el mejor método de desacreditación era tildarla de falsa o adulterada".
Por su parte en una hoja suelta, calzada con las iniciales F.P, el agente Penzotti contraatacaba recomendando su Biblia por ser esta traducida de manera fiel desde las lenguas originales. Censuraba y reprobaba los comentarios de la Iglesia Católica y ofrecía un premio de quinientos pesos oro al que pudiera demostrar "que la Biblia protestante es adulterada". ${ }^{63}$ Pero El Católico respondía siempre con la desacreditación del adversario como argumento principal: 
Un apóstata lujurioso, Martín Lutero, fue el fundador del protestantismo. Otros apostatas lujuriosos le hicieron coro. Un apóstata, también lujurioso, hace propaganda hoy a las falsas doctrinas de aquellos; Lujuria, soberbia, insurrección, he ahí el alma el protestantismo. Castidad, humildad, obediencia, he ahí el alma del catolicismo. Para conocer la Verdad, basta tener ojos y oídos para poder ver y oír. ${ }^{64}$

En su oportunidad la caracterización del Protestantismo se asoció

también a otras formas de pensar, como el Racionalismo:

La Iglesia Católica posee un distintivo tan particular, tan exclusivo de ella... Se trata de la virtud... de la santidad... La Iglesia católica continua produciendo santos desde el día de su nacimiento, pero el protestantismo no los produce desde el día de su nacimiento... la incredulidad y el racionalismo, desconocen la santidad... ${ }^{65}$

Pero el imaginario no estaba completo, había que perfilar aún más al enemigo, asociándole la mayoría de los males que amenazaban

la sociedad. El nuevo aliado del Protestantismo sería ahora el Liberalismo, en realidad, un producto suyo, a juicio de los católicos:

El germen del libre examen de Lutero produjo en su desarrollo el liberalismo, y este, pasando por el socialismo, llego a la última consecuencia, que es el nihilismo. Todo esto muy lógico, pese a quien pesare; y así tenía que suceder y ha sucedido; lo comprueba la historia y lo que hoy nos está pasando. ${ }^{66}$

Coincidían entonces los católicos con muchos estudios clásicos de nuestro tiempo, especialmente los trabajos de Laski (1936) y Merquior (1991), en el sentido de que la Reforma Protestante del siglo XVI sirvió, al igual que otros fenómenos políticos, culturales y sociales, a la formación del Liberalismo. ${ }^{67}$ Pero siendo el Liberalismo precisamente uno de los más grandes enemigos de la Iglesia Católica, se servía del imaginario colectivo ya forjado en contra de éste, para desacreditar los protestantes. Se apela también a un sentimiento racial en contra de los protestantes y a la propagación de su doctrina como mero mercantilismo; se asocia la confrontación Catolicismo-Protestantismo a la de un conflicto cósmico entre las fuerzas satánicas y las divinas: 
Sajones y Germanos fueron protestantes, los latinos no lo han sido ni podrán serlo jamás; y cuando yo veo a los mercaderes de Biblias ofreciendo su mercancía en las ciudades latinas hoy, me cause risa y les miro con el más alto desprecio, pues los latinos son refractarios el protestantismo por carácter... Satanás que conoce a los hombres y las razas, había vencido entre germanos y sajones, al menos por tres siglos, pero los latinos eran la causa de su tormento y de su pesar, y preparó la revolución latina, poniendo como base como es costumbre, la falsa libertad, la Libertad del Empíreo, la libertad del Paraíso, la Libertad del libre examen de Lutero... ${ }^{68}$

Un interesante aspecto de la estrategia de ataque al Protestantismo es la tendencia de El Católico a asociar manifestaciones diversas de las distintas "sociedades de ideas" como mutuas colaboradoras en el trabajo de oposición al catolicismo. Pretendía también establecer que el ataque protestante es contra la unidad religiosa, base de la autonomía nacional de Centroamérica. Apela al patriotismo, haciendo mención que en el acta constitutiva de independencia se estableció que la reli- gión oficial es la católica, y que es ésta la que debe mantenerse vigente por siempre, ya que éste había sido el deseo de los fundadores de la patria: que "la religión católica que hemos profesado en los siglos anteriores y profesaremos en los siglos sucesivos se CONSERVE PURA E INALTERABLE, manteniendo vivo el espíritu de religiosidad que ha distinguido siempre a Guatemala (Centro América) respetando los ministros eclesiásticos, seculares y regulares..." ${ }^{69}$; y añade:

No fueran temibles por sí solas esas insidias ni esos conatos, pues se atenta contra la fe firme de nuestros pueblos y contra el desprestigio de sus principios. Pero algunos hijos desnaturalizados de la patria, inspirados por el liberalismo o la masonería, se ponen de acuerdo con los predicantes cismáticos, los apoyan, los favorecen, entregándoles así traidoramente los intereses más caros de la República. ${ }^{70}$

No será pues extraño que de un momento a otro, se nos presenten aquí, como en Nicaragua y en Costa Rica, franca o solapadamente, los tales misioneros y misioneras protestantes para catequizarnos, vendiendo o regalando sus biblias y folletos, predicando en los hoteles y aun las esquinas de las calles sus blasfemias contra nuestros dogmas 
sacrosantos. No será extraño que, de un momento a otro, los periódicos radicales y masónicos comiencen a alabar y a recomendar a tales emisarios y a sus doctrinas, así como también que algunos salvadoreños desnaturalizados favorezcan y apoyen su propaganda. ${ }^{71}$

Los temores de El Católico resultaron ser fundados, pues solo mes y medio después escribían sobre el trabajo de Penzotti en El Salvador de la siguiente manera:

La acogida que han dado los periódicos liberales, la masonería y los libre pensadores no puede ser más satisfactoria. La prensa liberal lo ha saludado como a un gran señor. $Y$ recomendado sus predicaciones como fuentes de purísima luz. Los masones andan, de acá para allá, y de allá para acá, a la orden y al servicio del Reverendo señor Ministro Protestante. Los libre-pensadores se disputan el honor, que al fin tuvo el señor Méndez, según dicen, de que su sala sirviera de cátedra o de templo provisional para las conferencias y reuniones.

Desde luego que el liberalismo, la masonería y el libre pensamiento se conciertan con el referido ministro protestante, ya se deja ver cuál es el espíritu que lo anima contra la Iglesia: "Dime con quién andas y te diré quién eres."72

Nada haría por si sólo el R. Penzotti, pues nada tiene, según dicen, que lo recomiende ni que pueda llamar la atención en su favor. Pero sus amigos liberales, masones y librepensadores, que tanto le ayudan y tanto le sirven, son los que más contribuyen a su buen negocio y al feliz éxito de sus empresas. ${ }^{73}$

Mientras tanto, el periódico seguía defendiendo los más altos intereses de la Iglesia Oficial:

Así es que, el cuerpo de la nación será siempre católico, cualquiera que sea su porvenir y el progreso a que pueda llegar. En segundo lugar, las pequeñas agrupaciones disidentes que existen o pueden existir en el país, no tienen derecho a que el Estado modifique su constitución en el sentido de su separación de la Iglesia Católica... Esta 
constante usurpación de los bienes de la Iglesia por los gobiernos imbuidos en los principios de la secta protestante, demuestran hasta la última evidencia, que la libertad es nombre vano, una palabra sin sentido; y que la separación de la Iglesia del Estado significa la absorción de todos los derechos y las libertades de aquella. Es un error, pues la separación de la Iglesia del Estado en un país católico como el nuestro. ${ }^{74}$

En la lucha contra el Protestantismo, unir a Protestantes, Francmasones ${ }^{75}$, Liberales y Librepensadores como un enemigo común, daba a la Iglesia Católica la ventaja de adherir a los protestantes todo el imaginario que en años pasados -cuando el Protestantismo se consideraba una realidad lejana-, había construido contra los demás disidentes. Fortalecía su oposición y proveía argumentos adicionales para su desacreditación de cara a su feligresía. Seguramente esta asociación de ideas no era gratuita. Queda pendiente investigar las razones causales o casuales, así como los puntos de coincidencia por las que estas disidencias se extendieron apoyo muyo, siendo que sus respectivas ideologías no eran siempre necesariamente coincidentes.

Pero el trabajo de oposición de El Católico parece que tuvo sus efectos. En el Reporte Anual del año 1899 se encuentra un informe que si bien contiene una visión positiva del punto de distribución al que se había llegado, no oculta las tremendas consecuencias que para su trabajo había tenido la oposición del catolicismo.

En el curso de siete años la Agencia de Centro América ha pasado a través de las tres etapas de novedad, crisis y re-acción. El corazón humano es tentado a considerar el primero como una feliz adquisición, el segundo como una caída, y el tercero como triunfo... Hemos ahora llegado a la mejor parte - el triunfo, aunque debe admitirse que podemos estar equivocados.

Cuando Mr. Norwood y yo hicimos nuestro viaje de exploración en1892, tuvimos mucho éxito en la venta por la novedad, pero es bien sabido que el clero Católico Romano persigue las Escrituras más de lo que Saúl persiguió a David $^{76}$, y fueron capaces de destruir quizás las tres cuartas partes de ellas. Cuando salimos al terreno de nuevo, encontramos el trabajo más difícil y las ventas más bajas, y si ellos 
no nos pusieron en prisión y quemaron nuestros libros, fue porque las leyes no lo permiten. Muchas veces cuando los sacerdotes incitaron al pueblo las autoridades intervinieron y evitaron problemas. ${ }^{77}$

Y en el año 1900, listó las dificultades encontradas en el área de Centro América de la siguiente manera: "La oposición de sus enemigos, la pobreza de la gente, el Analfabetismo, la enfermedad del hombre debido al clima, la dificultad de encontrar colportores" ${ }^{78}$ Finalmente, en febrero de 1899, la ABS en New York solicitó a Francisco Penzotti viajar a Cuba para establecer el trabajo base para la reapertura de la Agencia cubana por lo que abandonó definitivamente la región centroamericana.

Sin embargo, en el año 1896, cuando Penzotti aún trabajaba en Centro América, un pastor protestante de nacionalidad norteamericana perteneciente a la "Sociedad de Amigos" en los Estados Unidos, confesión de fe más conocida como los Cuáqueros, solicitó y le fue concedida autorización para trasladarse a El Salvador y formar aquí una base misionera trabajando para una Organización formada en 1891 cuyo nombre era Central American Mission (Misión Centro Americana $)^{79}$. Venía de trabajar aproximadamente 25 años en Tamaulipas, México, desde el año 1871 a la fecha. En ese lugar había trabajado en la formación de escuelas, fundado iglesias e instalado una imprenta para publicar materiales de soporte a su trabajo. De manera especial, fundó un periódico al cual Ilamó La Rama de Olivo. Arribó en Acajutla el 12 de Julio de 1896, en el Vapor "City of Panama", y su llegada quedó registrada bajo el nombre de "S. A. Purdis", proveniente del puerto de Manzanillo, México. ${ }^{80}$

Hasta ese día todos los esfuerzos protestantes en el país habían girado fundamentalmente en torno a la distribución de Biblias por medio de los Agentes de la SBA. Las razones de ese comportamiento no proselitista de la Organización debería ser considerada como un objeto de estudio aparte en el presente, ya que en los movimientos protestantes actuales el movimiento proselitista a favor de sus respectivas denominaciones religiosas parece ser la clave del éxito en su trabajo. La llegada de este misionero se constituyó, entonces, como el primer esfuerzo misionero organizado en El Salvador, entendiendo como tal el hecho de que sus Misioneros no solo promovían la Biblia, sino también predicaban el evangelio. El objetivo de Purdie y de la Organización bajo cuyos auspicios llegó al país, fue la de "llevar el Evangelio a toda criatura en Centro América" a través de un esfuerzo evangélico no denominacional ${ }^{81}$. Gobernaba por esos días en El Salvador un Presidente de 
ideología liberal, el General Rafael Antonio Gutiérrez, por lo que el ambiente político era propicio. El agente Penzotti de la SBA describió la situación en San Salvador y la llegada de Purdie en estos términos:

Creo que este Estado es el más pequeño pero el más densamente poblado no sólo de Centro América, sino de toda Latino América. Su gobierno es progresista y liberal, pero la Iglesia Romana, como hace una amante en esta situación, se defiende a sí misma por todos los medios posibles, y no olvida su máxima "el fin justifica los medios". Afortunadamente el gobierno nos protege, y parece simpatizar con nuestro trabajo. He dedicado algún tiempo en la capital, Santa Ana, y otras ciudades con buenos resultados. En Julio el Rev. S. A. Purdie llegó a la capital para abrir una estación en conexión con la Misión Centro Americana... He tenido el placer de unirme con él en las primeras reuniones, y yo lo encuentro dispuesto en todo aspecto para prestar su cooperación. ${ }^{82}$

Samuel Purdie relata sus primeras experiencias en El Salvador con un recuento bastante detallado de la influencia del catolicismo como religión popular y de lo que él considera manifestaciones idolátricas. Describe El Salvador como un país "bajo la influencia del Ca- tolicismo, y los adherentes de esta última, secreta sino abiertamente opuestos a la introducción del Protestantismo en medio de ellos" ${ }^{83} \mathrm{El}$ 15 de enero de 1897, Purdie recibe en su habitación la visita de Francisco Penzotti con quien:

...fuimos exitosos en abrir reuniones en un salón en la parte central de la ciudad, y también en mi residencia, de tal manera que ahora tenemos dos congregaciones, una milla de distancia aparte. Además los días pasados han sido de los más interesantes de mi vida, y nunca había tenido una audiencia más atenta y cultivada. Cerca de 120 personas han escuchado el mensaje del evangelio. La asistencia ha sido de entre 30 a 40 en cada lugar cada reunión. El periódico El Católico dedicó casi una página entera citando y respondiendo nuestros discursos. Me he encontrado aquí con mas oposición que en mi trabajo previo en México, pero ha habido una gloriosa apertura, donde una cuantas semanas atrás parecía estar herméticamente sellado. ${ }^{84}$ 


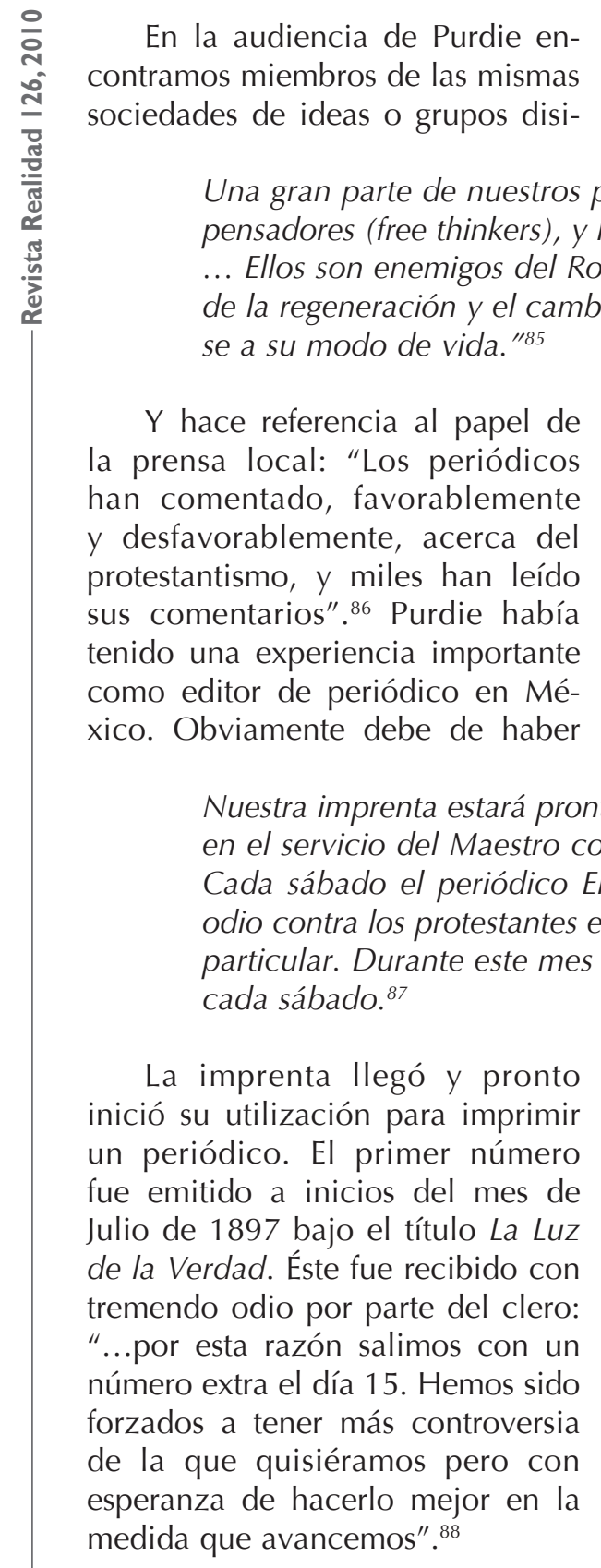
se a su modo de vida." ${ }^{85}$
$Y$ hace referencia al papel de la prensa local: "Los periódicos han comentado, favorablemente y desfavorablemente, acerca del protestantismo, y miles han leído sus comentarios". ${ }^{86}$ Purdie había tenido una experiencia importante como editor de periódico en México. Obviamente debe de haber cada sábado. ${ }^{87}$
La imprenta llegó y pronto inició su utilización para imprimi un periódico. El primer número fue emitido a inicios del mes de Julio de 1897 bajo el título La Luz de la Verdad. Este fue recibido con tremendo odio por parte del clero: “...por esta razón salimos con un número extra el día 15. Hemos sido de la que quisiéramos pero con esperanza de hacerlo mejor en la medida que avancemos" ${ }^{88}$ forzados a tener más controversia dentes que años atrás había reportado El Católico para Penzotti:

Una gran parte de nuestros primeros escuchas fueron libre pensadores (free thinkers), y libre bebedores (free drinkers), ... Ellos son enemigos del Romanismo, pero la predicación de la regeneración y el cambio de vida no parece adecuar-

considerado la prensa escrita como herramienta muy valiosa, tanto para apoyar su trabajo, como para refutar el de El Católico. El 3 de mayo de 1897, Purdie escribió lo siguiente en el Boletín Centro Americano, órgano oficial de divulgación del trabajo de la Misión Centro Americana en los Estados Unidos:

Nuestra imprenta estará pronto aquí y esperamos sea usada en el servicio del Maestro contra las fortalezas de Satanás. Cada sábado el periódico El Católico hecha espuma con odio contra los protestantes en general y contra nosotros en particular. Durante este mes se han sostenido conferencias

El 1 de Agosto de 1897, Purdie escribió una carta a un amigo que residía en México, la cual parece resumir la importancia y los efectos de la prensa y las publicaciones escritas en general en los procesos de construcción de la realidad y los imaginarios colectivos en las sociedades latinoamericanas, así como de la creación de espacios de debate abiertos, propios de una sociedad civil vigilante y organizada: 
Hemos tenido bastante controversia abierta a través de los periódicos, pero parece que han cesado totalmente. Mientras no teníamos prensa ellos nos atacaban en cada periódico, y cuando nuestro primer número de periódico salió, ellos aporreaban de una manera terrible como si quisieran comernos vivos. Mi "Librito en el que los errores de los Romanistas son refutados por Santos Papas y Concilios" salió a la luz y toda controversia terminó. Si ellos tienen algo que decir es en términos generales en contra de los protestantes en tiempos de Lutero. ${ }^{89}$

Samuel Purdie falleció de tétano a pocas semanas de la publicación del primer número de su periódico en San Salvador. La tarea de combatir la influencia católica por medio de la prensa fue retomada por sus más cercanos colaboradores. Sin embargo, la importancia

de los medios escritos para formar opinión, construir realidad y formar imaginarios colectivos a la base de la confrontación católico-protestante había quedado establecida y continuaría por muchos años. El Boletín Centro Americano, lo reportó de esta manera:

Una imprenta ha sido asegurada y nuestro hermano Purdie ha comenzado la publicación de La Luz de la Verdad en Julio de 1897, y también ha publicado algunos tratados. La pequeña banda ha sido reforzada por el hermano Bender en Marzo y todo promete un rápido y duradero progreso. ${ }^{90}$

\section{Reflexiones finales}

La prensa escrita ha sido, sin duda, una herramienta poderosa para la construcción de imaginarios colectivos. El catolicismo la utilizó durante el siglo XIX y de manera permanente con el objeto de atacar a todos sus adversarios, entre los que se encontraba el Protestantismo. Como se ha podido observar, los disidentes del clero católico trabajaron unidos para abrir espacio a la secularización en El Salvador. Es manifiesta la actitud del catolicismo en unir en un frente común a las Sociedades Protestantes, Liberales y Francmasones. Al presente, el uso de la prensa escrita sigue jugando roles similares. En la medida que la libertad de prensa esté presente y exista la mayor cantidad de agentes de la sociedad que tengan acceso a la opinión pública a través de la prensa, se generaran los contrapesos necesarios para construir una democracia sana y viva, donde los intereses de todos se vean representados. 
La posición del periódico católico también abona a líneas de investigación muy poco tratadas $-y$ quizás inédita- en El Salvador. Debe ahondarse en el rol de las sociedades disidentes del catolicismo en la formación de un Estado moderno en El Salvador; el rol de estas disidencias en la conformación de espacios públicos de opinión y su aporte a la construcción de una sociedad civil fuerte y comprometida. También es importante el examen de las diversas formas de cooperación entre grupos disidentes como el Protestantismo y la Masonería, impensables en nuestro tiempo, y las razones por las que al presente no sólo son inexistentes sino fundamentalmente antagónicas. Este ensayo también abre espacios para la reevaluación de las teorías de la conspiración que señalan el fenómeno del Protestantismo en El Salvador y Centroamérica como un esfuerzo del imperialismo norteamericano financiado y sostenido desde fuera, mientras vemos que los indicios hablan de iniciativas propias de organizaciones protestantes independientes con visiones del mundo muy propias y no asociadas necesariamente a la práctica del poder establecido en los Estados Unidos.
Sin embargo el objetivo fundamental de este ensayo ha sido evidenciar el rol de los periódicos en la formación de imaginarios colectivos. Especialmente sobre el que impera en la relación de confrontación, aun vigente en nuestros días, entre protestantes y católicos. Es un hecho que la imagen protestante delineada a través de un periodismo como el que representa El Católico, tuvo la oportunidad de insertarse con tal fuerza que hasta nuestros días mucha de la misma prevalece.

En la actualidad se espera que las Iglesias sean fuentes de inspiración en la creación de valores para el desarrollo de una sociedad más justa. Trabajando aparejados con otros agentes de la misma sociedad, se espera también que puedan ser catalizadores que lleven a cabo las grandes transformaciones sociales y económicas que tanto anhelamos. Pero las mismas Iglesias evangélicas deben reflexionar sobre su identidad, afirmándola e incorporándose a estos procesos largos y difíciles. Es mi convicción que el descubrimiento de la realidad del pasado, podrá servir de base para la transformación hacia una vida más fructífera del quehacer eclesial en el presente. 
NOTAS

American Bible Society, Eighty First Annual Report of the American Bible Society, New York, American Bible Society, 1897, p. 101.

2 Con el término Misiones Protestantes aludiré en este ensayo a dos manifestaciones del Protestantismo, presentes ambas en El Salvador a finales del siglo XIX, pero cuyos objetivos difieren en mucho del sentido que en la actualidad se entiende por misiones protestantes como organizaciones dedicadas al proselitismo religioso y la expansión denominacional. Estas son la Sociedad Bública Americana y la Misión Centroamericana. Ninguna de las dos tiene dentro de sus objetivos fundacionales hacer proselitismo religioso o denominacional. Véase: American Bible Society, Constitution of the American Bible Society. New York, 1916, y Central American Mission, The Central American Bulletin, Dallas, Texas, Vol. 1, No.3. Fundada en 1880 , los primeros cuatro boletines de la Misión Centroamericana se imprimieron sin fecha de publicación, por el contexto del contenido se puede deducir que este ejemplar fue impreso en 1884.

Cfr. Augustin Cochin, Les Sociétés de pensée et la démocratie. Etude d'bistoire révolutionnaire, Paris, Plon-No urritet Cie, Imprimeurs-Editeurs, 1921 y Francois Furet, Pensar la Revolución francesa, Barcelona, Ediciones Petrel, 1980.
4 Jean Pierre Bastian (compilador), Protestantes, liberales y francmasones. Sociedades de ideas y modernidad en América Latina, siglo XIX, México, Fondo de Cultura Económico, 1990, pp. 7-8. Cursivas en el original.

El Católico fue fundado en Junio de 1881 bajo los auspicios de la Sociedad San Vicente de Paúl. El administrador de El Católico era el comerciante Francisco Prado. El periódico surge en el contexto de la lucha en contra de la laicización de la educación que había implementado por el entonces Presidente Rafael Zaldívar. Cfr. Jorge Araujo Lozano, La Iglesia Salvadoreña y la laicización de la educación 1881: ¿Un proyecto liberal frente a una respuesta ultramontana? Tesis de Maestría en Filosofía Iberoamericana, Universidad Centroamericana "José Simeón Canas”, El Salvador, 2008.

6 American Bible Society, Jubilee Memorial of the American Bible Society: Being a review of its first fifty years' work. New York, American Bible Society, 1867, p. 6.

Este objetivo quedo consignado en su misma Constitución, Cfr. American Bible Society, Constitution of the American Bible Society formed by a Convention of Delegates. Literal I, New York, 1816. La Sociedad Bíblica Americana (SBA) es una organización sin fines de lucro, interconfesional, no denominacional fundada en 1816 la ciudad de Nueva York, la cual publica, distribuye y traduce la 


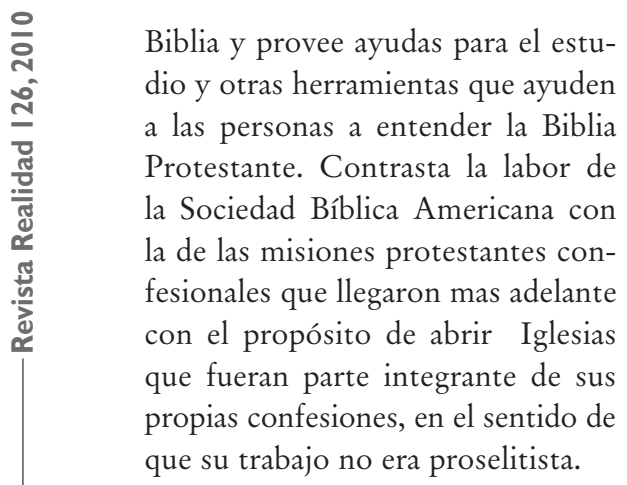

8 Dorothy U. Compagno, Distribution in Latin America, 1861-1900, ABS Historical Essay \#15, Part V-C-2, The Caribbean area: Central America, Venezuela and Colombia, and the West Indies. Copyrigth ã 1965 by American Bible Society, p. 1.

$9 \quad$ Cfr. "Thirthy Eighth Annual Report of the American Bible Society", presentado el 11 de Mayo de 1854, en American Bible Society, Annual Report of the American Bible Society, with an Account of its Organization, Vol. III, New York, American Bible Society, 1861, p. 82. Las fuentes originalmente escritas en idioma Inglés, han sido libremente traducidas al castellano por el autor de este ensayo.

10 Cfr. "Forty Fourth Annual Report of the American Bible Society", presentado el 10 de Mayo de 1860, en American Bible Society, Annual Report of the American Bible Society, with an Account of its Organization, Vol. III, New York, American Bible Society 1861, p. 624.
Cfr. "Forty Seven Annual Report of the American Bible Society", presentado el 14 de Mayo de 1863, en American Bible Society, Annual Report of the American Bible Society, with an Account of its Organization, Vol. III, New York, American Bible Society, 1861, p. 854. Hay una inconsistencia en el fechado de este Volumen III el cual es una recopilación de Reportes de la ABS. La pagina principal presenta la recopilación como publicada en 1861 pero contiene un reporte de fecha 1863 , que es posterior. El libro pertenece a la Biblioteca de la Universidad de California, catalogada al número 9116, bajo la categoría de Missions, recibido en la Universidad en Diciembre 18 de 1872. En cuanto a la nacionalidad de Mr. Frederick Hicks, las fuentes que se han tenido a disposición no proporcionan indicativo alguno de su nacionalidad, pero se presume que era norteamericano.

Hay que tener presente, sin embargo, que la calificación de los líderes políticos salvadoreños en dos categorías, sea como "liberales" o como "conservadores", ha sido señalada como inadecuada: "El régimen de Gerardo Barrios, a juicio de Adolfo Bonilla, más que liberal puede denominarse "absolutista" pues buscó la transformación sociopolítica del país a través del culto a su personalidad, la violencia a cualquier precio, utilizando el método del despotismo ilustrado." Cfr. Sajid Herrera, "¿Liberales contra conservadores? Las 
facciones políticas en El Salvador del siglo XIX”, en Boletín AFEHC, http://afehc-historia-centroamericana.org/index.php? action $=\mathrm{fi}_{\text {}}$ aff\&id=1836, parrafo 7, Febrero 2008. Véase la cita de Adolfo Bonilla en "La búsqueda de la reconstrucción centroamericana, 1841-1855", en Álvaro Magaña (Coordinador), El Salvador. La República, 1808-1923, 2000, pp. 132-141.

13 Citada en Dorothy U. Compagno, Distribution in Latin America, 18611900 , p. 3.

14 Ibíd.

Cfr. el "Forty Seventh Annual Report of the American Bible Society", presentado el 14 de Mayo de 1863, en American Bible Society, Annual Report of the American Bible Society, with an Account of its Organization, Vol. III, New York, American Bible Society, 1861, p. 854. En cuanto a la nacionalidad de Mr. William Norris, las fuentes que se han tenido a disposición no proporcionan indicativo alguno de su nacionalidad, pero se presume que era norteamericano.

17 Citada en Dorothy U. Compagno, Distribution in Latin America, 18611900, p. 4.

18 Para muchos historiadores contemporáneos clasificar a Dueñas como conservador no es lo más

aproximado a la realidad, sino como "liberales constitucionalistas" o liberal-católicos. Véase, por ejemplo, Sajid Herrera, "¿Liberales contra conservadores? Las facciones políticas en El Salvador del siglo XIX.” AFEHC, Febrero 2008, http:// afehc-historia-centroamericana.org/ index.php? action $=$ fi_aff\&id $=1836$.

Dorothy U. Compagno, Distribution in Latin America, 1861-1900, p. 5.

Ibíd.

Ibíd., p. 12.

Ibíd. Aunque el original en Ingles utiliza la palabra "libros" (books), se presume que eran Biblias, dado que era el producto fundamental de la venta de la SBA. Por otro lado la referencia a "San Salvador" por parte del Cónsul de Los Estados Unidos en el Departamento de La Unión, debe probablemente referirse a la República, pues en muchos reportes de la época de la SBA se utiliza San Salvador en lugar El Salvador.

Ibíd., p. 15.

Ibíd., p. 36.

American Bible Society, SeventySeventh Annual Report of the American Bible Society, New York, American Bible Society, 1893, pp. 27-28.

Ibíd., pp. 90-91. 


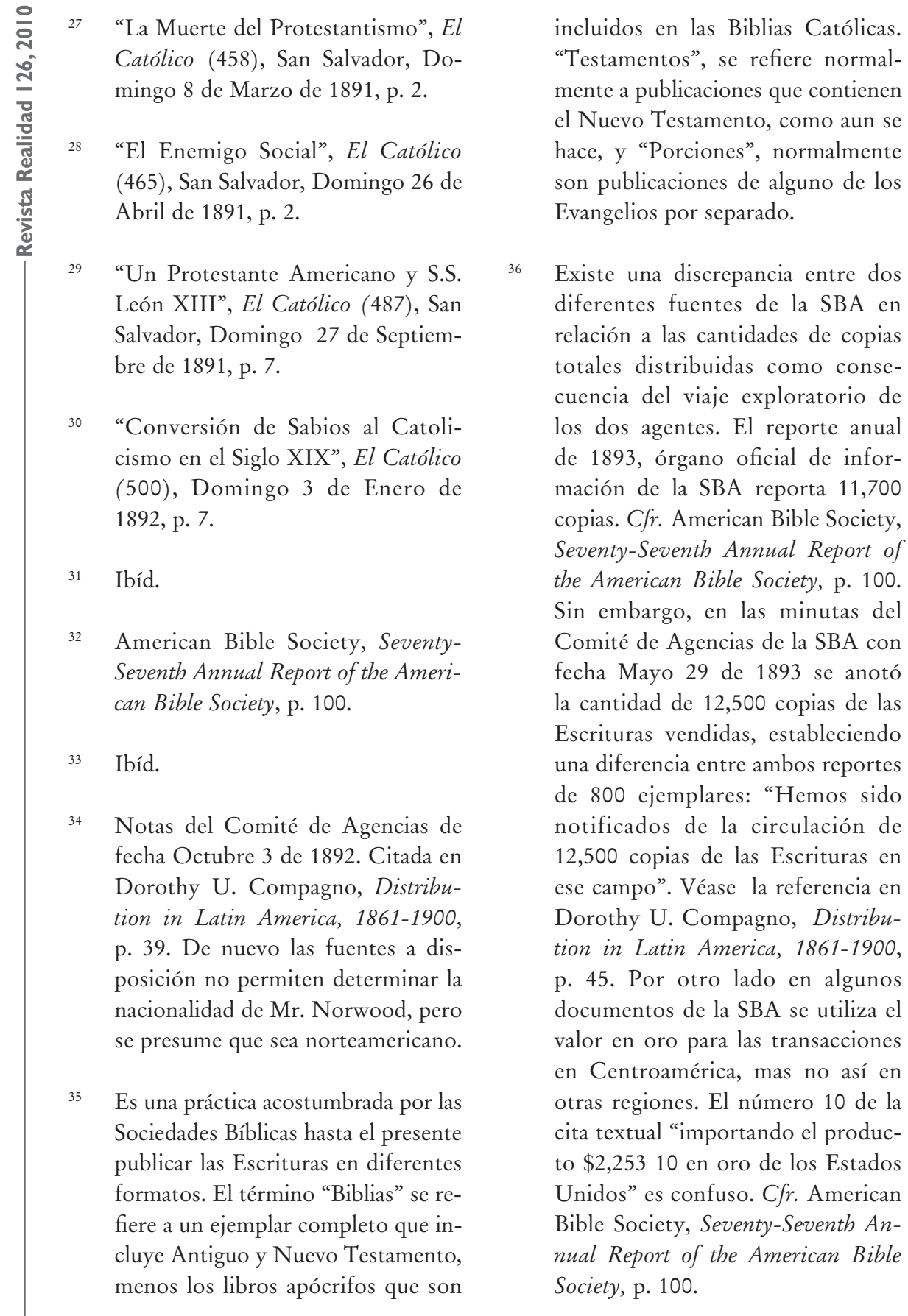


Véase la frase escrita por parte del Comité de Agencias de la SBA de fecha Febrero 27 de 1893 en Dorothy U. Compagno, Distribution in Latin America, 1861-1900, p. 45.

El nombre "Colportor" se deriva etimológicamente del latín comportare o transportar. Aplica a los vendedores ambulantes que cargaban las mercancías y cargas pesadas en los hombros. En ese sentido, se utiliza para designar a los vendedores de Biblias ambulantes cuyo trabajo se realiza de casa en casa.

47 American Bible Society, Eighty First Annual Report of the American Bible Society, New York, American Bible Society, 1897, pp. 99-100.

Cfr. Dorothy U. Compagno, Distribution in Latin America, 1861-1900, p. 81.

"La Prensa Religiosa en Centro América”, El Católico (528), San Salvador, Domingo 24 de Julio de 1892, p. 4.

"Como se estableció en Protestantismo”, El Católico (562), San Salvador, Domingo 19 de Marzo de 1893 , p. 7

"El Maestro Aquel”, El Católico (559), San Salvador, Domingo 26 de Febrero de 1893, p. 7.

52

53

54 sector céntrico de la ciudad de San Salvador. A solo unos metros al norte del Instituto Nacional y de la Central de Telégrafos; a pocos metros del Palacio Municipal y a corta distancia del Palacio Episcopal. Francisco Penzotti era un experimentado Agente de la SBA y se ubicó estratégicamente, pues 


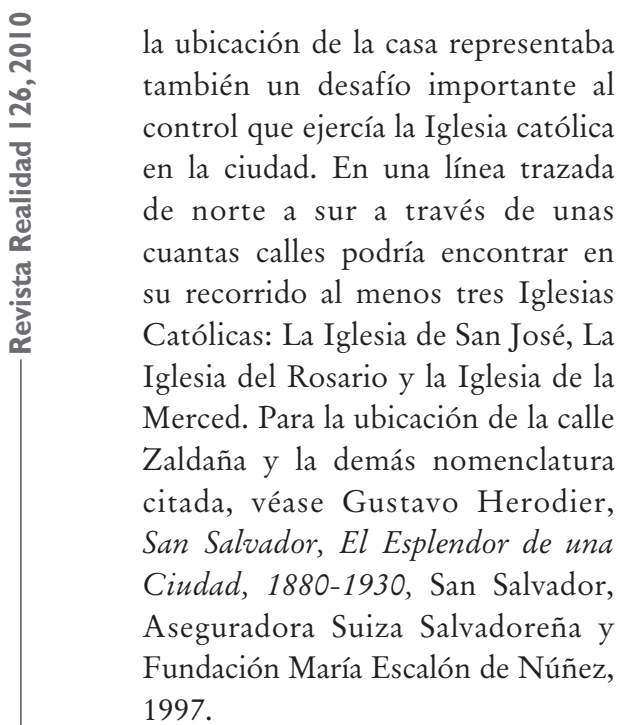

"Como se estableció el Protestantismo”, El Católico (562), San Salvador, Domingo 19 de Marzo de 1893, p. 8.

El Católico reforzó su capacidad de defensa reproduciendo el contenido que traían sobre los Protestantes los periódicos extranjeros. El 9 de Abril del año en cuestión, ofrece al público en general la subscripción a una gran variedad de periódicos religiosos en la Librería Moral y Religiosa de Federico Prado y Cía. Entre ellos podemos nombrar: La Hormiga de Oro de Barcelona, semanario ilustrado; La Revista Popular de Barcelona, semanario ilustrado; La Bomba Final de Zaragoza; La Controversia de Madrid; Las Misiones Católicas de Barcelona; La Cruz de Madrid; El Católico de San Salvador, El Pueblo Católico de Santa Tecla; La Semana Católica de Guatemala, entre otros.
Véase, "Periódicos Religiosos", El Católico (565), San Salvador, Domingo 9 de Abril de 1893, p. 7.

"La propaganda protestante en la diócesis de El Salvador”, El Católico (561), San Salvador, Domingo 12 de Marzo de 1893, p. 4.

${ }^{61}$ "Sabemos que ha comenzado a dar sus conferencias; que a una de ellas asistieron como treinta personas, $y$ entre ellas unas cuatro ó cinco mujeres desconocidas. Agregan que el señor doctor Don Rafael Reyes era uno de los mas notables asistentes”, Cfr. " La propaganda protestante en la diócesis de El Savador”, El Católico (561), San Salvador, Domingo 12 de Marzo de 1893. Con toda seguridad este notable no era otro sino el masón Rafael Reyes. Para mayores datos sobre la identidad masónica de Reyes, puede consultarse Roberto Armando Valdés Valle, Masones, liberales y ultramontanos salvadoreños: Debate político y constitucional en algunas publicaciones impresas, durante la etapa final del proceso de secularización del estado salvadoreño. Tesis para optar al grado de Doctor en Filosofía Iberoamericana. Universidad José Simeón Cañas, mayo de 2010.

${ }^{62}$ "La propaganda protestante en la diócesis de El Salvador”, El Católico (561), San Salvador, Domingo 12 de Marzo de 1893, p. 4.

63 Esta hoja suelta se transcribe en las páginas del periódico, cursivas en el 
original. Cfr. "Atrás la impostura", El Católico (561), San Salvador, Domingo 12 de marzo de 1893, p. 4.

64 "Diócesis de Nicaragua. Un Templo Protestante”, El Católico (561), San Salvador, Domingo 12 de Marzo de 1893 , p. 5.

65 "Revista del Movimiento Católico XII”, El Católico (577), San Salvador, Domingo 3 de Julio de 1893, p. 1.

"Revista del Movimiento Católico XXIV”, El Católico (600), San Salvador, Domingo 4 de Febrero de 1894, p. 1.

Laski sostiene que el liberalismo "No hubiera llegado a ser lo que fue sin la revolución teológica que llamamos la Reforma", véase Harold J. Laski, El liberalismo europeo, México, Fondo de Cultura Económica, 1936, p. 12. Por su parte, Merquior formuló esta misma idea de la siguiente manera: "Normalmente se asocia la cultura moderna con la abundancia de derechos individuales... Seguramente podemos buscar las raíces del liberalismo en la experiencia histórica de la modernidad... Admitiendo que la escala y el crecimiento del individualismo son una marca distintiva de la modernidad... El gran culpable original era Lutero, que había desencadenado el demonio del individualismo", Jose Guilherme Merquior, Liberalismo Viajo y Nuevo, México, Fondo de
Cultura Económico, 1991 (cursiva en el original), p.33.

"Revista del Movimiento Católico", El Católico (583), San Salvador, Domingo 8 de Octubre de 1893, p. 2.

"El Protestantismo en Centroamérica”, El Católico (627), San Salvador, Domingo 7 de Octubre de 1894, p. 1. Cursivas y mayúsculas en el original.

El Protestantismo en San Salvador", El Católico (634), San Salvador, Domingo 25 de Noviembre de 1894, p. 2.

Ibíd., p. 3.

74 "La Separación de la Iglesia del Estado”, El Católico (645), San Salvador, Domingo 10 de Febrero de 1895, p. 1.

En El Salvador, la instalación de la primera Logia masónica, "Progreso $\mathrm{N}^{\circ} 5$ " tuvo lugar el 30 de Septiembre de 1871. Para un planteamiento sobre el papel de la Masonería en las transformaciones del Estado salvadoreño durante el siglo XIX, véase: Roberto Armando Valdés Valle, Masones, liberales y ultramontanos salvadoreños: Debate político $y$ constitucional en algunas publicaciones impresas, durante la etapa 


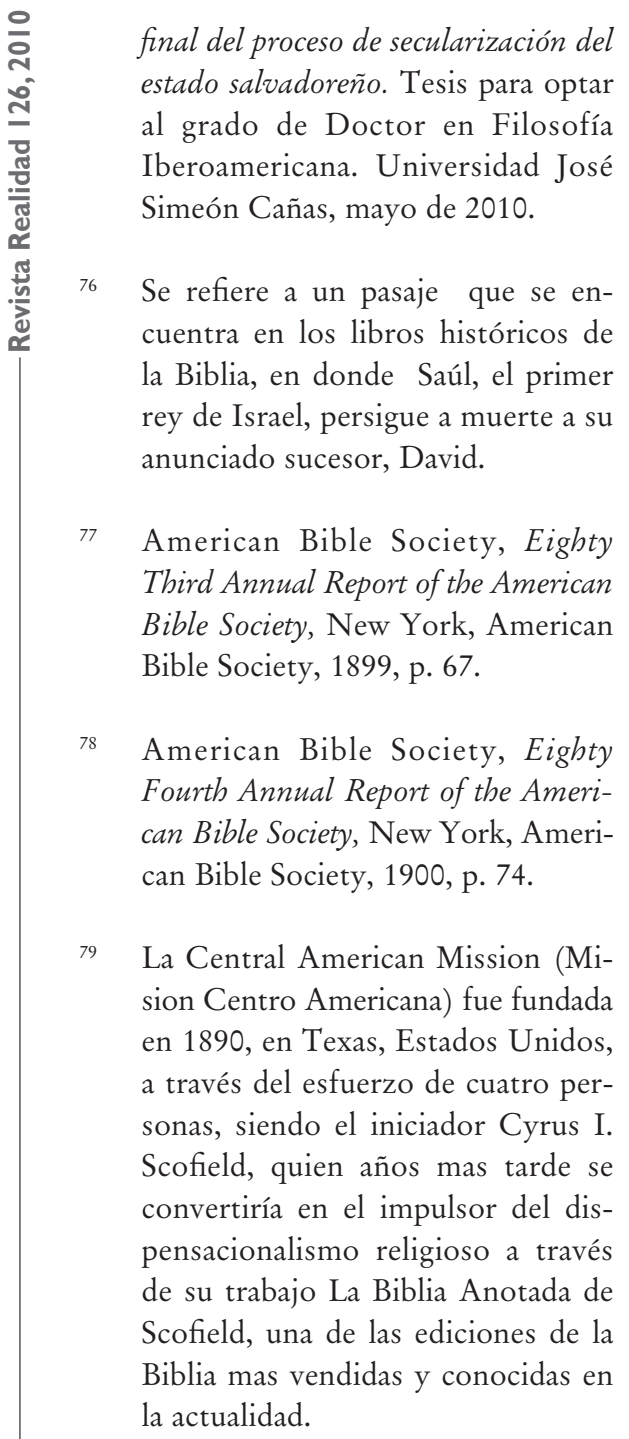

80

"Movimiento de Buques", Diario Oficial (164), Tomo 41, San Salvador, Lunes 13 de Julio de 1896, p. 1155. El nombre del buque que transportó al misionero Samuel E. Purdie es diferente en dos fuentes. Purdie anotó en su diario personal

el nombre del vapor "Barreconta". Si bien la fecha de llegada coincide, el nombre del vapor que está anotado en el Diario Oficial de esa fecha es "City of Panama", proveniente de Manzanillo, México. Finalmente, en el registro del apellido se anotó "Purdis" y no "Purdie" como efectivamente debió ser.

The Central America Bulletin, Published by the Central American Mission, 1891,Vol 1, No.1, p.1. Por no denominacional entendemos que la "Central American Mission" (Misión Centro Americana) no formaba parte ni pertenecía a ninguna confesión de fe, iglesia protestante o grupo religioso alguno. Sino que era un esfuerzo llevado a cabo por personas seculares deseosas de cumplir con su llamado cristiano a difundir el evangelio.

American Bible Society, Eighty First Annual Report of the American Bible Society, New York, American Bible Society, 1897, p. 101.

James Purdie Knowles, The New Field. Samuel A. Purdie. His Life and Letters. His Work as a Missionary, Plainfiled, Indiana, Publishin Association of Friends, 1908, p. 220.

84
Ibíd., p. 229.

Ibíd., p. 230.

Ibíd., p. 231.

Ibíd., p. 232. 
$89 \quad$ Ibíd. p. 235.

90 Reporte sobre la continuación del trabajo de impresión fundado por Purdie, Cfr. "Central American Mission”, Central American Bulletin, Agosto 7, 1897. 